\title{
Impact of aortic annulus geometry according to ISO 5840:2019 (draft) on hydrodynamic performance of transcatheter aortic valve prostheses
}

\begin{abstract}
To assess the hydrodynamic performance of transcatheter aortic valve prostheses (TAVP), in vitro test using pulse duplicators is required. Test conditions as well as minimum performance criteria are specified in ISO 58403:2013 and ISO 5840-3:2019-draft. In the 2019 published draft, modifications regarding hydrodynamic testing are proposed. Among others, the geometrical configuration of the fixation has changed, with the intention to improve the anatomical representation as well as the comparability of results from different test laboratories.
\end{abstract}

We analyzed the consequences of altered annulus fixations regarding native leaflets as well as a step in the proximal area of the protheses to prevent their migration. The analyses were conducted with regard to the degree of calcification of the annulus ring on hydrodynamic parameters. By using 3D stereolithography printing technology, molds for casting of silicone elastomer of annulus models with and without native leaflets were manufactured. A modular system enabled us to use the same annulus ring to model the degree of calcification as well as different step sizes. We performed in vitro hydrodynamic testing according to ISO 5840-3:2019-draft of a selfexpandable valve prototype with porcine pericardial leaflets by using a commercially available pulse duplicator system.

As expected, regurgitation increases with increasing degree of calcification, whereby the use of a step has no influence on the backflow of fluid during diastole. The effective orifice area (EOA) of the valve showed a clear

\footnotetext{
*Corresponding author: Jan Oldenburg: Institute for ImplantTechnology and Biomaterials e.V., Friedrich-Barnewitz-Str. 4, 18119 Rostock-Warnemünde, Germany, e-mail: jan.oldenburg@uni-rostock.de Sebastian Kaule, Stefan Siewert, Klaus-Peter Schmitz, Michael Stiehm: Institute for ImplantTechnology and Biomaterials e.V., Friedrich-Barnewitz-Str. 4, 18119 Rostock-Warnemünde, Germany

Niels Grabow: Institute for Biomedical Engineering, Rostock University Medical Center, Friedrich-Barnewitz-Str. 4, 18119 Rostock-Warnemünde, Germany
}

tendency with respect to radial protrusion of the step. The EOA decreased as the radial protrusion increased. We also present a suggestion to prevent migration without affecting the general test results, by using a novel step design. We also found that the novel annulus model with native leaflet drastically reduced the regurgitation.

Keywords: ISO 5840, aortic valve, TAVP, TAVI, annulus aortic fixture, hydrodynamic

https://doi.org/10.1515/cdbme-2020-3117

\section{Introduction}

Transcatheter heart valve prostheses (TAVP) are used to treat valve stenosis and insufficiency. Due to good clinical performance, extensions of therapy from high risk to intermediate risk patients are discussed [1]. In order to predict the clinical performance of the TAVP, their hydrodynamic characteristics are tested in vitro by using pulse duplicator systems. Pulse duplicator systems simulate the left heart circulatory system with clinically relevant pulsatile characteristics. These testing systems are wellestablished and are accepted as gold standard for in vitro hydrodynamic performance characterization [2].

The ISO 5840-3 defines requirements, test conditions as well as minimum criteria for aortic valves [3]. A draft, introduced in 2019 to update this standard, includes changes of in vitro hydrodynamic testing [3]. The draft also includes a more precise specification of the fixation of the valve in the test system. The fixation, also called aortic fixture or annuls model, is intended to mimic the anatomical features of the human annulus region. This includes the implantation diameter, the annulus thickness and leaflet geometry. Comparing to the former aortic fixture design, the novel design differs in modelling a native leaflet configuration as well as a nodule as pathological alteration caused by plaque or calcification. Since the annulus models are technical replicas of anatomical conditions, unexpected problems may 
occur. For instance, there may be a proximal migration of the valve in the annulus model during testing.

The consequences resulting from different interpretation of the normative requirements in accordance to aortic fixture on the one hand and major changes, e.g. regarding the specification of the fixation on the other hand, makes it difficult to objectively compare the results obtained from hydrodynamic tests using different fixtures.

The prevention of migration as well as the general shape of the annulus model described in the draft, especially the recently proposed geometry of the native leaflets, was analyzed in this study.

\section{Materials and methods}

\subsection{Geometry and manufacturing of aortic annulus models}

The geometry of the annulus models is in accordance with the specifications of the latest draft of the ISO 5840-3:2019. The aortic fixture composed of a ring, which represents the annulus environment, including the appropriate annular plane. In distal direction from the annular plane, there are cylindrical structures supposed to mimic the native leaflets. Figure 1 schematically illustrates the geometric parameters of such a fixation. The minimum shore hardness of the used material should not be less than 10A [4]. If it is intended to treat aortic stenosis with the valve device, the calcification of the aortic annulus should also be considered. Additionally, we established an "anti-migration step", the step is supposed to prevent proximal migration of the device during hydrodynamic testing, see figure 1 . The ISO standard does not prescribe any kind of step, but due to the absence of regulatory constraints for the inflow region, a manufacturer may argue that such a step could be used due to its necessity.
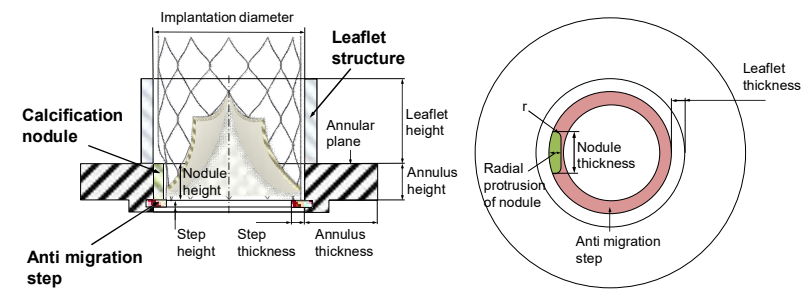

Figure 1: Schematic representation of the aortic annulus fixture for hydrodynamic testing; in cross sectional view (left), and in proximal top view (right).
Specifications for the design of the aortic fixation are shown in Table 1. The ISO specifications are compared to the annulus models manufactured and examined within the current study.

We manufactured annulus models with and without leaflets. Furthermore, the step thickness was varied. The step consists of a solid ring, which could be inserted into a groove in the annulus model. In this way, the radial protrusion of the step was changed stepwise by using the same modular aortic fixture. Moreover, a customized anti-migration step was designed and manufactured, see Figure 2.

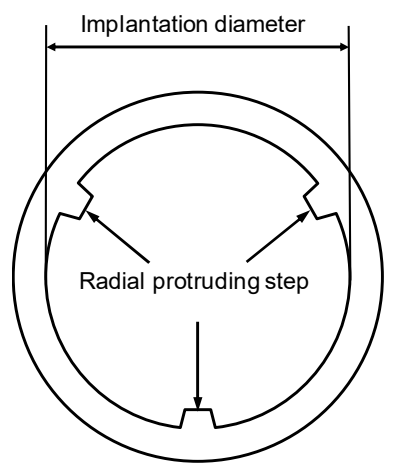

Figure 2: Schematic illustration of the 3-point step to prevent proximal migration during hydrodynamic testing (radial protrusion $=2 \mathrm{~mm}$ )

Furthermore, the degree of calcification was varied from $1.5 \mathrm{~mm}$ radial protrusion with $1.5 \mathrm{~mm}$ corner radius to $2 \mathrm{~mm}$ radial protrusion with $0.2 \mathrm{~mm}$ corner radius.

Table 1: Specifications of geometric annulus model; parameters according to ISO 5840-3:2019 draft in comparison to manufacturing parameters of the annulus model within the current work.

\begin{tabular}{|c|c|c|c|}
\hline \multicolumn{2}{|l|}{ Parameter } & $\begin{array}{l}\text { Specifications ISO } \\
5840-3: 2019 \text {, draft }\end{array}$ & $\begin{array}{c}\text { Specification } \\
\text { annulus model }\end{array}$ \\
\hline \multicolumn{2}{|c|}{ Implantation diameter } & $\begin{array}{l}\text { min - max diameter } \\
\text { recommended per } \\
\text { product specification }\end{array}$ & $\begin{array}{l}\text { only max diameter } \\
(26 \mathrm{~mm})\end{array}$ \\
\hline \multirow[b]{2}{*}{ Annulus } & thickness & minimum $4 \mathrm{~mm}$ & $10.5 \mathrm{~mm}$ \\
\hline & height & $5-7 \mathrm{~mm}$ & $6.4 \mathrm{~mm}$ \\
\hline \multirow[b]{2}{*}{ Lealfet } & thickness & $1-2 \mathrm{~mm}$ & $2 \mathrm{~mm}$ \\
\hline & height & $\begin{array}{c}0.5 \text { * implantation } \\
\text { diameter }\end{array}$ & $13 \mathrm{~mm}$ \\
\hline \multirow{4}{*}{$\begin{array}{l}\text { Calcification } \\
\text { nodule }\end{array}$} & thickness & minimum 4 mm & $4 \mathrm{~mm}$ \\
\hline & height & equal annulus height & $6.4 \mathrm{~mm}$ \\
\hline & $\begin{array}{l}\text { radial } \\
\text { protrusion }\end{array}$ & minimum 1.5 mm & $1.5 \mathrm{~mm}$ and $2 \mathrm{~mm}$ \\
\hline & corner radius & maximum $1.5 \mathrm{~mm}$ & $\begin{array}{c}1.5 \mathrm{~mm} \text { and } 0.2 \\
\mathrm{~mm}\end{array}$ \\
\hline \multirow{2}{*}{$\begin{array}{l}\text { Anti migration } \\
\text { step }\end{array}$} & $\begin{array}{l}\text { radial } \\
\text { protrusion }\end{array}$ & & $\begin{array}{l}\text { without, } 1 \mathrm{~mm} \text {, } \\
2 \mathrm{~mm}, 3 \mathrm{~mm}\end{array}$ \\
\hline & height & not intended & $2 \mathrm{~mm}$ \\
\hline
\end{tabular}

All annulus models were manufactured using a silicone elastomer casting process (Sylgard 170 Silicone Elastomer, Dow Corning, Midland, MI, USA). The shore hardness of the 
material, as stated by the manufacturer, was $47 \mathrm{~A}$. The casting molds themselves as well as the anti-migration steps were manufactured by means of stereolithographic additive printing technology (3D-printer: Form 2, polymer: rigid resin, Formlabs Inc. Somerville, MA, USA.).

\subsection{In vitro hydrodynamic testing}

In order to investigate the different annulus geometries, hydrodynamic tests were carried out by using a commercial pulse duplicator system (HDTi 6000, BDC Laboratories, Wheat Ridge, CO, USA). A prototype of a self-expandable valve made of a nitinol frame with a sutured leaflet of porcine pericardium was used as test valve. Initially, the valve was crimped once before further testing. For testing the different annulus models the valve was manually implanted into the aortic fixture.

For all hydrodynamic measurements the following testing parameter were used: heart rate: $70 \mathrm{BPM}$, mean aortic pressure: $100 \mathrm{mmHg} \pm 2 \mathrm{mmHg}$, diastolic to systolic pressure difference: $40 \mathrm{mmHg} \pm 2 \mathrm{mmHg}$, systolic duration: $35 \%$, cardiac output: $51 / \mathrm{min} \pm 0.2 \mathrm{ml}$, test solution: $0.9 \%$ saline, temperature: $37^{\circ} \mathrm{C} \pm 2^{\circ} \mathrm{C}$.

According to ISO standard $n=10$ cycles were recorded for each measurement. Each annulus configuration was examined three times.

Characteristic hydrodynamic metrics of the valve depending on the aortic fixture were derived from the measured values of the pressure and volume flow curves. These included the effective valve opening area (EOA) and the regurgitation (backward flow over the valve). The calculations of the characteristic values were carried out in agreement with ISO 5840-3:2019 (Draft) [4].

\section{Results and discussion}

\subsection{Effect of leaflet structure on hydrodynamic valve performance}

Annulus models with and without leaflet were compared, to examine the effect of the leaflets that has recently been updated in the standards. The average regurgitation, each from three measurements, is shown in Table 2.
Table 2: Regurgitation volume measured by means of pulse duplicator system for hydrodynamic characterizing of an TAVP with and without leaflet geometries on the aortic fixture.

\begin{tabular}{lcc}
\hline Annulus type & Mean regurgitation $[\mathrm{ml}]$ & $\begin{array}{c}\text { Standard } \\
\text { deviation }[\mathrm{ml}]\end{array}$ \\
\hline $\begin{array}{l}\text { Without native } \\
\text { leaflets }\end{array}$ & 23.83 & 0.14 \\
\hline $\begin{array}{l}\text { With native } \\
\text { leaflets }\end{array}$ & 6.86 & 0.20 \\
\hline
\end{tabular}

With identical implantation height of the valves into the annulus models the regurgitation increased considerably in case of no native leaflets. We assume that the native leaflet serves as a sealing, resulting in a considerably reduced regurgitation.

\subsection{Impact of anti-migration step size and calcification on hydrodynamic metrics}

Here the use of an anti-migration step was studied. Four different step designs (step radial protrusion: $1 \mathrm{~mm}, 2 \mathrm{~mm}$, $3 \mathrm{~mm}$ and 3-point step) were manufactured and analyzed based on the hydrodynamic results. The corresponding regurgitation volumes are shown below in Fig. 3. The annulus ring without step (step radial protrusion: $0 \mathrm{~mm}$ ) was used as a reference.

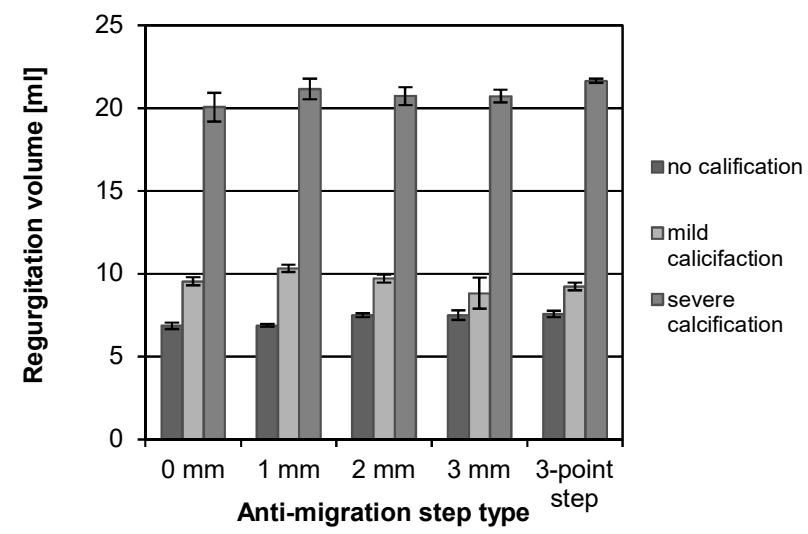

Figure 3: Regurgitation volume of transcatheter aortic valve prosthesis in annulus models with different anti-migration step types (step radial protrusion: $1 \mathrm{~mm}, 2 \mathrm{~mm}, 3 \mathrm{~mm}$ and 3-point step) and varying degree of calcification (no calcification; mild calcification: radial protrusion $1.5 \mathrm{~mm}$, corner radius: $1.5 \mathrm{~mm}$; severe calcification: radial protrusion $2 \mathrm{~mm}$, corner radius: 
$0.2 \mathrm{~mm}$ ), data shows means \pm standard deviation of $n=30$ cycles.

In General, a clear correlation between regurgitation volume and degree of calcification can be seen. As the degree of calcification increases, the total regurgitation volume increased from approximately $7.2 \mathrm{ml}$ to over $20 \mathrm{ml}$. Compared to the degree of stenosis, the influence of the step size was negligible. Thus, no major difference can be detected when using a step.

The effective valve opening area is shown in Fig. 4 depending on the size of the step and the degree of calcification.

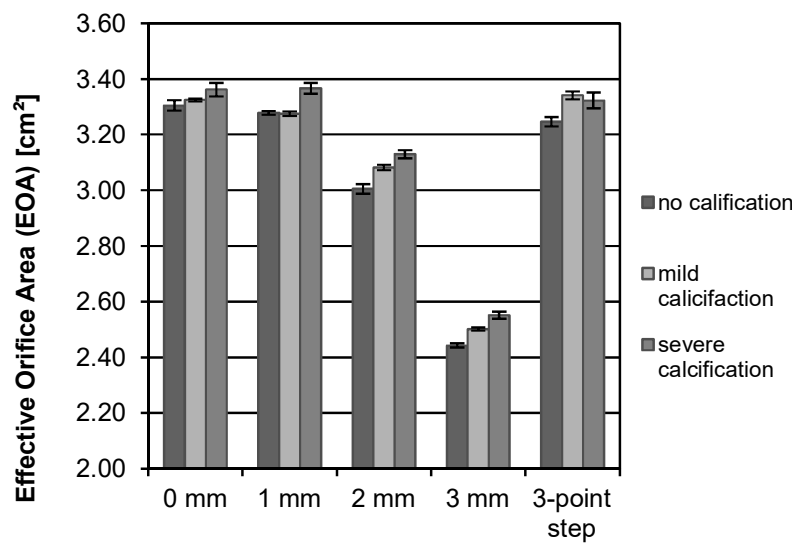

Anti-migration step type

Figure 4: Effective Orifice Area of transcatheter aortic valve prosthesis in annulus models with different anti-migration step types (step radial protrusion: $1 \mathrm{~mm}, 2 \mathrm{~mm}, 3 \mathrm{~mm}$ and 3-point step) and varying degree of calcification (no calcification; mild calcification: radial protrusion $1.5 \mathrm{~mm}$, corner radius: $1.5 \mathrm{~mm}$; severe calcification: radial protrusion $2 \mathrm{~mm}$, corner radius: $0.2 \mathrm{~mm}$ ), data shows means \pm standard deviation of $\mathrm{n}=30$ cycles.

A clear tendency of the reduction of EOA in connection with the increase of the radial protrusion of the step was seen. For example, without stenosis, EOA is reduced from $3.3 \mathrm{~cm}^{2}$ (without step) to $2.44 \mathrm{~cm}^{2}$ (with $3 \mathrm{~mm}$ step) meaning a reduction of $26 \%$. The reason for the reduction in EOA might be a decreased effective flow cross-section due to the radial step protrusion.

On the basis of the presented valve characteristics, a step of up to $1 \mathrm{~mm}$ radial protrusion as well as a 3-point step can be applied which does not influence the test outcome. Furthermore, it was evident that a specific 3-point step design adapted to the valve could be considered feasible. There was no noticeable change in regurgitation volume or EOA compared with the reference measurement.

\section{Conclusion}

The new requirements for hydrodynamic testing of the ISO 5840-3:2019-draft marks important aspects in order to ensure consistency of inter-laboratory testing. In particular, the precise description of the aortic fixture is strengthening the gold standard of this test method as an in vitro performance test. In order to evaluate the changes of the proposed aortic fixture, hydrodynamic tests were conducted. As reference, results obtained by using the former fixture design were compared. We have shown that the provided leaflet structure had a major influence on TAVR regurgitation. The leaflet probably acts as a sealing around the valve. Secondly, we have demonstrated that a step, designed for the prevention of proximal migration of the valve during testing, can have an influence on the overall hydrodynamic characteristics. Based on the presented results, we recommend the use of a step of less than $1 \mathrm{~mm}$ height or even the use of a valve design matching step geometry, such as the presented 3-point step design. The results presented may not be simply transferable to other types of valves, thus the exact effect, such as an anti-migration step for the valve to be tested, should be evaluated on each individual test case.

\section{Author Statement}

Financial support by the European Regional Development Fund (ERDF) and the European Social Fund (ESF) within the collaborative research between economy and science of the state Mecklenburg-Vorpommern, by the Federal Ministry of Education and Research (BMBF) within RESPONSE "Partnership for Innovation in Implant Technology" is gratefully acknowledged. Conflict of interest: Authors state no conflict of interest. Informed consent and ethical approval are not applicable.

\section{References}

[1] Leon M, Smith C, Mack MJ et al. Transcatheter or Surgical Aortic-Valve Replacment in Intermediate-Risk Patients. N Engl J Med. 2016;347(17):1609-20.

[2] Wu C, Saikrishnan N., Chalekian A.J. et al. In-Vitro Pulsatile Flow Testing of Prosthetic Heart Valves: A Round Robin Study by the ISO Cardiac Valves Working Group. Cardiovascular Engineering and Technology, 2019,10:397422.

[3] Deutsches Institut für Normung ISO 5840-3: 2013, Cardiovascuar implants - Cardiac valve prostheses - Part 3: Heart valve substitutes implanted by transcatheter techniques.

[4] Deutsches Institut für Normung ISO 5840-3: 2019, Cardiovascuar implants - Cardiac valve prostheses - Part 3: Heart valve substitutes implanted by transcatheter techniques. 